\title{
Determination of Quality Requirements in Tourism Management and Finance Departments of Akhmet Yassawi University by Kano Model ${ }^{1}$
}

\author{
Dinmukhamed Kelesbayev \\ Kuatbek Kalykulov \\ Rima Yermankulova \\ Botagoz Dandayeva
}

Akhmet Yassawi University, Turkestan, Kazakhstan

Email: dinmukhamed.kelesbayev@iktu.kz

\section{Alima Aymurzayeva}

Gazi University, Ankara, Turkey

\section{Doi:10.5901/mjss.2015.v6n3s1p34}

\begin{abstract}
In this study the information was given regarding Kano's Model and a case study was conducted for university students. Kano's Model was applied for Akhmet Yassawi University students and it was questioned what they thought were important quality requirements in higher education, the degree of their importance and how they evaluated their own institutions with respect to the quality requirements. The purpose of this study is to determine the student requirements regarding the quality of the undergraduate programs of Tourism Management and Finance in Akhmet Yassawi University and to analyze the student satisfaction and dissatisfaction and their majority roles in determining and improving the quality of the programs. To achieve this object, firstly Kano's Survey was applied to 116 students and the student requirements relating to the education were uncovered by focusing on group work. Secondly, these requirements were classified by Kano Evaluation Table. Thus, the quality requirements divided into four categories: must-be, one-dimensional, attractive and indifferent. Finally, the values of satisfaction and dissatisfaction were calculated and the roles of these requirements in increasing and decreasing student satisfaction and dissatisfaction were identified clearly.
\end{abstract}

Keywords: quality in higher education; quality requirements; tourism management; finance; Kano model.

\section{Introduction}

The quality concept as "quality is the customer wants" (Peters, 1999: 6) which has become an important factor of ongoing competition in many areas, which mostly takes into account the groups of customers or the buyers of the university services, and products. One of these groups is university students of present and future times (Pourhasomi et al. 2012: 236). In order to succeed in today is market it should be better to understand customer requirements and they must be satisfied (Jiao and Chen, 2006: 177-178). Now universities increasingly began to use customer-oriented methods to improve possible requirements together with already existing requirements of students ie, customer satisfaction service of clients (Kuo et al. 2011: 12017). Therefore, the factors affecting the formation of student satisfaction is very important and it is necessary to know thoroughly (Liu and Wu, 2009: 482). However, there are critical problems of universities needs, which their students do not know in details. The approach used in this context, is one of the Kano model. This model is able to meet the needs of business customers with the degree of relationship between customer satisfaction reveals (Matzler and Hinterhuber, 1998: 28). Accordingly, this business needs to determine the quality of their products; you can take advantage of improvements (Harvey, 1995: 163). Generally, studies in this field is not used too much of this model emphasizes the importance of the work done. In this study, information on whether Kano Model is a case study was conducted for university students. Kano Model has been described in detail to the students and all things about what they think on higher education quality requirements, the requirements in terms of their significance and how they evaluate their

\footnotetext{
1 This article was supported by the Research Project of Khoja Ahkmet Yassawi International Kazakh-Turkish University.
} 
own institutions were examined.

\subsection{Aim}

The aim of this study relates to the quality of the undergraduate departments of Tourism Management and Finance in Akhmet Yassawi University:

- to show students requirements influential in the formation of student satisfaction according to Kano model,

- to classify this quality requirements basing on the Kano Evaluation Table,

- to analyze the role of student satisfaction and dissatisfaction in improving the quality of the program.

\subsection{Scope and limitations of the study}

The scope of this study is limited with the undergraduate departments of Tourism Management and Finance in Akhmet Yassawi University. In total, there are 116 students in these departments. The purpose of these departments is to train specialists, academicians, teachers or lecturers (http://econ.iktu.kz, 25.10.2014). The cause of this chapter research is to contribute to the students' views and to develop more effective strategies for the purpose of achieving better quality in the process of tourism management and finance.

\subsection{The value of the study}

The quality of higher education is a matter, which is saving its actuality in the world. When opportunities and benefits of higher education provided for people were taken into consideration, creation of solutions to these problems is important for education system, as well as for individuals.

On the other hand, it is also observed that there is a serious competition among universities despite of problems related to quality. One of the foremost elements in a competitive environment is the concept of quality. When the quality concept of "quality is the customers wants" began to be defined, universities had taken into more account the students as recipients of services or customer. In order to reach the fact of higher education quality the great importance of students is needs at this point. Students, at the end of a serious and systematic study determined requirements, to ensure quality in education decision-makers provide great opportunities.

Therefore, the factors affecting the formation of student satisfaction is very important and it is necessary to know thoroughly. However, the critical problem is that universities do not know about the needs of their students and the importance of this requirement level in details. For these reasons, study in this field is not researched too much; this model emphasizes the importance of the work.

\section{Theoretical Framework}

\subsection{Kano model}

Kano model (see Figure 1) was developed in 1984 by Japanese professor Noriaki Kano and colleagues (Kano et al., 1984) to classify customer requirements. Professor Kano said that the quality requirements of products and services are not equal in the eyes of their customers (Matzler and Hinterhuber, 1998: 27; Tan and Shen, 2000: 1143). Kano Model reveals the relationship between the degrees to which functions meet customer requirements with customer satisfaction (Lofgren and Witell, 2005: 11; Lofgren and Witell, 2008: 63). This model is that one, which identifies the reason of ordinary improvement of customer satisfaction level despite of big improvement in other customer requirements meet in contrast other customer satisfactions are extremely increased when a little improvement is provided in some customers, meet the needs (Matzler and Hinterhuber, 1998: 28; Tan and Shen, 2000: 1145; Liu and Wu, 2009: 483; Dominici and Palumbo, 2013: 90). 


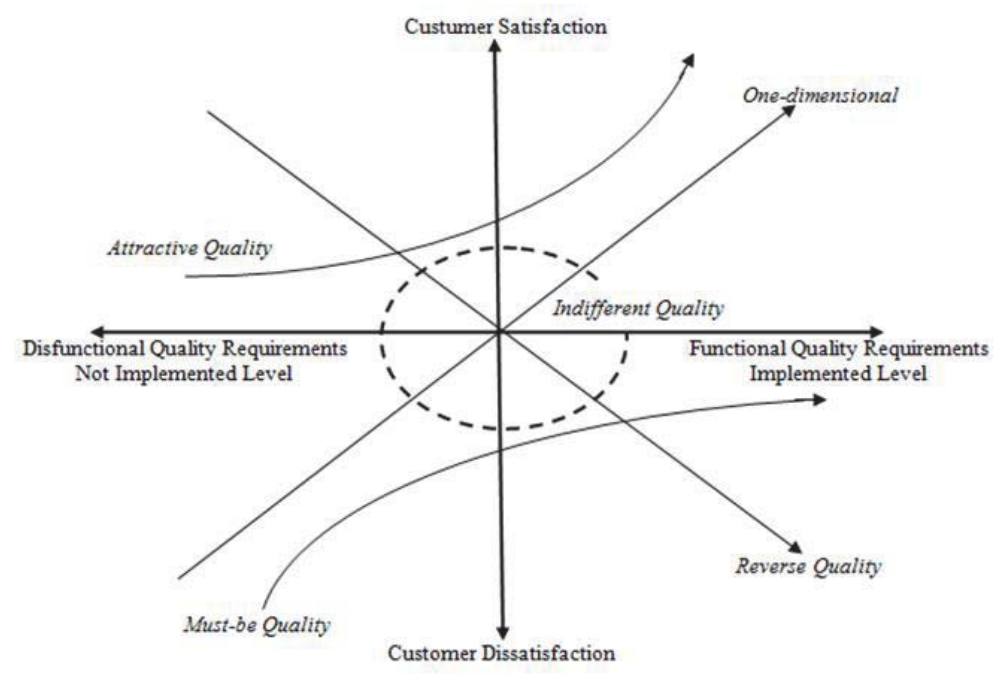

Figure 1. Kano scheme (Walden (Ed.), 1993: 4; Matzler and Hinterhuber, 1998: 29)

\subsection{Kano scheme}

As seen in Figure 1, the horizontal axis indicates how much successful the quality requirements of the product or service were in meeting customer expectations. If the axis moves to the right, it meets more the customer expectations of quality requirements; if it moves to the left, we can see that it meet less. In addition, vertical axis indicates customers satisfaction level related to products and services quality requirements. The more the axis moves upward, the more degree of customer satisfaction is high, the more the axes moves down, the more customer dissatisfaction is so high.

\subsection{Kano categories}

Basing on the axis of Kano schema, based on product or service quality requirements Kano Model divided into six separate categories and each of these six categories in a different way affected customer satisfaction. These are (Walden (Ed.), 1993: 3-35; Matzler and Hinterhuber, 1998: 28-30; Tan and Pawitra, 2001: 421-422; Tan and Shen, 2000, p. 1,143-1144; Zulte and Mazur, 2006, p. 110-112; Dominici and Palumbo, 2013: 90-91; Liu, 2013: 134-135):

Must-be quality requirements $(\mathrm{M})$ : These requirements are the must-be criteria of products and services. If these requirements are not in the products and services, the customer will be extremely dissatisfied. On the other hand customers on products and services by seeing these requirements if the guarantee, it does not affect customer satisfaction. Therefore, these requirements only prevent customer dissatisfaction. For example, the restaurant is not clean, it causes on higher customer dissatisfaction, while being clean does not have any influence on customer satisfaction.

One-dimensional quality requirements (0): These requirements are directly proportional with the level of how much these requirements are. The high level of requirements fulfillment gives a high level of customer satisfaction or vice versa. Customers often explicitly request these requirements. For example, a feature expected by the customer in a car, that a car mile of indicators (diesel or gas consumption) is good. Better km indicator provides customer satisfaction, while a worse $\mathrm{km}$ indicator leads to customer dissatisfaction.

Attractive quality requirements (A): They have the greatest impact on customer satisfaction, quality requirements. This is not clearly stated by the customers' quality requirements and not expected. The fulfillment of these requirements provides more customer satisfaction. If these are not fulfilled, it leads to customer dissatisfaction. For example, when a car radio antenna turns off automatically the car customer feel high satisfaction, but does not descend into the car customer do not feel dissatisfaction. These requirements differ from the product stream and provide a competitive advantage.

In addition to these three main categories, there are three different quality requirements. They are indifferent. These are not the actual customer requirements can be referred to as the characteristic (Tontini, 2000: 728; Liu, 2013: 135-137). 
Indifferent quality requirements (I): Customer product or service is fully functional or dysfunctional, if not remain indifferent. Therefore, this requirement is not met does not make any sense for the customer, what is dissatisfied nor satisfied. For example, the cigarette lighter in a car that is not an important quality requirement.

Reverse quality requirements (R): This needs to be in by customer's products they want and they expect the exact opposite at the same time of need. For example, in normal conditions, in terms of getting the sun in the winter when requesting a house overlooking the south side, facing north to the distractions of summerhouse are preferred.

Questionable quality requirements (Q): This type of question quality requirements or wrongly stated or misunderstood by the customer is given an answer or unreasonable.

\section{Research Methods}

\subsection{Data collection: determination of quality requirements}

\subsubsection{Group-centered work}

The starting point of Kano Questionnaire is the identification and characterization of the creation of the survey, which will be held with research on product or service quality requirements. Griffin and Hauser (1993: 1-27) refer that interviews in a homogeneous market segment with only $20-30$ people (Group-centered work), about $90-95 \%$ of all quality requirements related to the product or service in customers minds quality.

Quality requirements related to educational services, which are presenting and will be presented in the university where students study at the Bachelor of Tourism Management and Finance Programs was obtained by qualitative study with group-centered works, which is one of the methods. Each of the two divisions, $1^{\text {st }}, 2^{\text {nd }}, 3^{\text {rd }}$ and $4^{\text {th }}$ classes, each class includes 1 female and 1 male students, in total 16 students and four (both class and individual) group-centered works (both group-centered works of 4 students: 2 male and 2 female) were conducted. Each group-centered work interviews lasted about 35 minutes.

\subsubsection{Questioannaire work}

After the determination of the quality requirements related to product or service of students and group-centered work, Kano questionnaire will be prepared in order to collect data on the quality requirements. Kano Questionnaire consists of two parts as functional and dysfunctional questions for each that is positive and negative (Walden (Ed.), 1993: 5). Table 1 presents an example of the Kano Questionnaire (see Table 1). As seen in Table 1, a question is given in two ways, including positive and negative, and five answer choices for each question. These answer choices mean as following: 1 I enjoy it, 2 - it should be, 3 - it does not matter, 4 - not bad yet, 5 - I do not like.

Students (116 students) of the undergraduate departments of Tourism Management and Finance in Social Sciences Faculty of Akhmet Yassawi University have been applied, and all of them were included. Questionnaire consists of two parts. The first department of students in the demographic characteristics belonging to the questions, while the second part group-centered work-studies obtained by the students of their educational services related to the quality requirements are met or not met in case they feel they have been asked.

Table 1. Sample Kano Questionnaire

\begin{tabular}{|c|c|c|c|}
\hline № & \multicolumn{2}{|r|}{ Question } & Answer \\
\hline 1 & $\begin{array}{l}\text { Functional Quality } \\
\text { Requirements (Positive) }\end{array}$ & $\begin{array}{l}\text { What do you feel if your car km indicator (gas or petroleum) is } \\
\text { in a good condition? }\end{array}$ & $\begin{array}{l}1 \text { - I like it } \\
2-\text { It should be } \\
3-\text { It does not matter } \\
4-\text { It is not bad yet } \\
5-\text { I do not like it }\end{array}$ \\
\hline 1 & $\begin{array}{l}\text { Disfunctional Quality } \\
\text { Requirements (Negative) }\end{array}$ & $\begin{array}{l}\text { What do you feel if your car km indicator (gas or petroleum) is } \\
\text { not in a good condition? }\end{array}$ & $\begin{array}{l}1 \text { - I like it } \\
2 \text { - It should be } \\
3 \text { - It does not matter } \\
4-\text { It is not bad yet } \\
5-\text { I do not like it }\end{array}$ \\
\hline
\end{tabular}

Reference: Walden (Ed.), 1993: 5; Matzler and Hinterhuber, 1998: 31 


\subsection{Data analysis: quality requirements classification}

\subsubsection{Kano evaluation table}

After determination of quality requirements related to the product or service and data collected requirements related to these requirements, each requirement will be defined what phase of Kano category it belongs, in other words they are classified. Quality requirements of each of the participants in the quastionnaire, two questions of Kano type (positive and negative) based on their responses are classified according to Kano Evaluation Table (see. Table 2). According to Table 2 of the quality, requirements, which are, belong to which categories. For instance; In Table 1, sample questions a customer positive for the question " 1 - I enjoy it," negative questions, "5 - I do not like answered," If such quality element categories according to Table 2 "O" is a category that is, the one-dimensional quality requirements in the category are included.

Table 2. Kano Evaluation Table

\begin{tabular}{|c|c|c|c|c|c|c|}
\hline \multirow{2}{*}{\multicolumn{2}{|c|}{ Quality Requirements of product or service }} & \multicolumn{5}{|c|}{ Disfunctional Quality Requirements (Negative) } \\
\hline & & \multirow{2}{*}{$\begin{array}{l}1-\text { I } \\
\text { like it } \\
Q\end{array}$} & \multirow{2}{*}{$\begin{array}{c}\begin{array}{c}2-\text { It } \\
\text { should be }\end{array} \\
\text { A }\end{array}$} & \multirow{2}{*}{$\begin{array}{l}3-\text { It does } \\
\text { not matter } \\
\text { A }\end{array}$} & \multirow{2}{*}{$\begin{array}{c}4-\text { It is not } \\
\text { bad yet } \\
\text { A }\end{array}$} & \multirow{2}{*}{$\begin{array}{l}5-\mathrm{I} \text { do } \\
\text { not like it } \\
\mathrm{O}\end{array}$} \\
\hline \multirow{5}{*}{$\begin{array}{c}\text { Functinal Quality } \\
\text { Requirements (Psitive) }\end{array}$} & $1-$ l like it & & & & & \\
\hline & 2 - It should be & $\mathrm{R}$ & I & 1 & 1 & $\mathrm{M}$ \\
\hline & 3 - It does not matter & $\mathrm{R}$ & I & I & I & $\mathrm{M}$ \\
\hline & $4-$ It is not bad yet & $\mathrm{R}$ & I & $\mathrm{I}$ & $\mathrm{I}$ & $\mathrm{M}$ \\
\hline & $5-I$ do not like it & $\mathrm{R}$ & $\mathrm{R}$ & $\mathrm{R}$ & $\mathrm{R}$ & Q \\
\hline \multicolumn{7}{|c|}{$\begin{array}{l}\text { M = Must-be Quality Requirements, I = Indifferent Quality Requirements, } \\
\mathrm{O}=\text { One-dimensional Quality Requirements, R = Reverse Quality Requirements, } \\
\text { A = Attractive Quality Requirements, Q = Questionable Quality Requirements, }\end{array}$} \\
\hline
\end{tabular}

Reference: Walden (Ed.), 1993: 6; Matzler and Hinterhuber, 1998:32

\subsubsection{Coefficients of satisfaction and dissatisfaction}

Quality requirements for each category of evaluation enter the simplest way to answer that is the statistical mode; frequency analysis is based on evaluation and interpretation. However, different market segments have different requirements because it is usually in some cases can be assigned to a specific category of quality requirements are not clear. In this case, may not be appropriate to use statistical mode. In such a case, satisfaction and dissatisfaction has been revealed that the coefficients (Walden (Ed.), 1993: 18). This is the case of the coefficients of formula (Matzler and Hinterhuber, 1998: 33):

Satisfaction $=\frac{A+O}{A+O+M+I} ;$ Dissatisfaction $=\frac{O+M}{(A+O+M+I) \times(-1)}$

Here is: $\mathrm{M}=$ Must-be Quality Requirements, I = Indifferent Quality Requirements,

$\mathrm{O}=$ One-dimensional Quality Requirements, $\mathrm{A}=$ Attractive Quality Requirements

Coefficient of satisfaction with products or services meet the quality requirements an increase in customer satisfaction how the coefficient of dissatisfaction in the quality requirement is not met, the customer is an indicator of how much dissatisfaction will occur. The satisfaction coefficient is in the range from 0 to 1 . A value closer to 1 greater impact on customer satisfaction and quality requirements contained in the mark of the bands, the coefficient is closer to 0 indicate a very small effect quality requirements. Likewise, the dissatisfaction factor -1 in the range of 0 . Closer to -1 , customer dissatisfaction marks a major impact on quality requirements in the bands, the coefficient is closer to 0 indicate that not lead to customer dissatisfaction (Matzler and Hinterhuber, 1998: 33).

The data obtained, Kano Evaluation Table and Satisfaction Factor with quality requirements are classified, after first must-be then one-dimensional and attractive quality requirements, $M>0>A$ such order of priority should be met (Walden (Ed.), 1993: 11; Dominici and Palumbo, 2013: 92). 


\section{Study Findings}

\subsection{Group-centered study findings}

Table 3. Quality Requirements Related to Students Higher Education

\begin{tabular}{|c|c|c|c|}
\hline № & First & № & Second \\
\hline \multirow{5}{*}{1} & \multirow{5}{*}{ 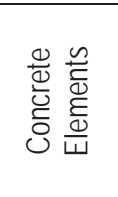 } & 1 & Nice and clean classrooms \\
\hline & & 2 & Modern educational-instructional equipments (for example, video projectors etc.) \\
\hline & & 3 & Lack of support services unit (for example: medical center, sports buffet, dormitories, etc..) \\
\hline & & 4 & Available of rich central library \\
\hline & & 5 & Available WiFi Access \\
\hline \multirow{6}{*}{2} & \multirow{6}{*}{ 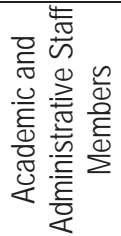 } & 6 & Presence of Academic Personnel at Departments \\
\hline & & 7 & Teachers come to the course and explain their own knowledge \\
\hline & & 8 & Theoretical and practical information of academic personnel must be updated \\
\hline & & 9 & Good teaching and communication skills of academic staff \\
\hline & & 10 & Student affairs optimum execution speed and carefully \\
\hline & & 11 & Presence of well-mannered and friendly academic staff \\
\hline \multirow{8}{*}{3} & \multirow{8}{*}{ 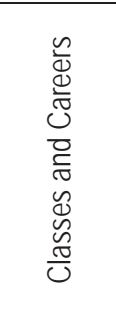 } & 12 & Accordance of discipline contents with future jobs of students \\
\hline & & 13 & Understandable and applicable of lessons \\
\hline & & 14 & Presence of lot of elective disciplines \\
\hline & & 15 & Correspondence of contents of examination questions with taught units \\
\hline & & 16 & Availability and transparency of examination evaluation standards \\
\hline & & 17 & Allocation of practices part with the test scores of students \\
\hline & & 18 & Opportunities and career planning for practice applications at the end of each academic year \\
\hline & & 19 & Organization of information seminars and available counseling offices for career planning application \\
\hline \multirow{5}{*}{4} & \multirow{5}{*}{ 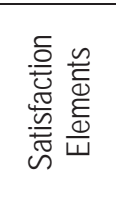 } & 20 & Presence of entertainment and shopping centers at University campus \\
\hline & & 21 & Information studies and a variety of language courses related to foreign language as TOEFL \\
\hline & & 22 & Accessible digital libraries and internationally accepted scientific sites at university or department \\
\hline & & 23 & Masters and PhD programs, information and preparatory classes for these programs \\
\hline & & 24 & Invitation of famous specialists and scientists to national and international seminars, conferences \\
\hline
\end{tabular}

As a result of the focus group study, higher education students about their education and training services grouped under four headings, the primary quality requirements are determined. These concrete elements, with academic and administrative staff, courses, and career and with the requirements of the qualification are elements. 24 pieces for each primary set of quality requirements has been identified secondary quality requirements. These are all shown in Table 3 (see Table 3).

\subsection{Application of Kano Model Findings}

Samples: According to the analysis of the demographic structure of the sample, female students $66,37 \mathrm{~s} \%, 33,63 \%$ are male and under 20 years of 58,62\%, 41,38\% was seen in the $20-25$ age range. According to the total monthly family income, the largest share in the distribution of income between $\$ 200-400$, with those who are middle-lower income level and the percentage of this group is $47,41 \%$. The incomes between $\$ 200-400$, upper-middle income group which is a percentage of $31,89 \%$. $25 \%$ of the students have undergone practical training in case. Almost all students want to do practicum. Finally, $20,69 \%$ of respondents $1^{\text {st }}$ form, $24,14 \%$ - $2^{\text {nd }}$ form, $26,72 \%$ - $3^{\text {rd }}$ form and $28,45 \%$ are $4^{\text {th }}$ form pupils. Structure of the sample is presented in detail in Table 4. 
Table 4. Demographic Structure of the Sample

\begin{tabular}{|c|c|c|c|c|}
\hline № & Formation & Distribution Group & Amount & $\begin{array}{c}\text { Percentage } \\
(\%)\end{array}$ \\
\hline \multirow{3}{*}{1} & \multirow{3}{*}{ Gender } & Female & 77 & 66,37 \\
\hline & & Male & 39 & 33,63 \\
\hline & & Total & 116 & 100 \\
\hline \multirow{4}{*}{2} & \multirow{4}{*}{ Age } & $\ldots \leq 20$ & 68 & 58,62 \\
\hline & & $20-25$ & 48 & 41,38 \\
\hline & & $25 \leq \ldots$ & 0 & 0 \\
\hline & & Total & 116 & 100 \\
\hline \multirow{5}{*}{3} & \multirow{5}{*}{$\begin{array}{l}\text { Total Monthly Incomes of Family } \\
\qquad(\$)\end{array}$} & $\ldots \leq 200$ & 14 & 0,14 \\
\hline & & $200-400$ & 55 & 47,41 \\
\hline & & $400-600$ & 37 & 31,89 \\
\hline & & $600 \leq \ldots$ & 10 & 0,10 \\
\hline & & Total & 116 & 100 \\
\hline \multirow{5}{*}{4} & \multirow{5}{*}{ Undergoing Practical Training } & Undergone Practical training & 29 & 25 \\
\hline & & Do not Undergo Practical Training & 87 & 75 \\
\hline & & Person who wants to undergo practical training & 112 & 96,56 \\
\hline & & $\begin{array}{c}\text { Person who does not want to undergo practical } \\
\text { training }\end{array}$ & 4 & 3,44 \\
\hline & & Total & 116 & 100 \\
\hline \multirow{5}{*}{5} & \multirow{5}{*}{ Course } & $1^{\text {st }}$ Course & 24 & 20,69 \\
\hline & & $2^{\text {nd }}$ Course & 28 & 24,14 \\
\hline & & $3^{\text {rd }}$ Course & 31 & 26,72 \\
\hline & & $4^{\text {th }}$ Course & 33 & 28,45 \\
\hline & & Total & 116 & 100 \\
\hline
\end{tabular}

Table 5. Kano Model Implementations

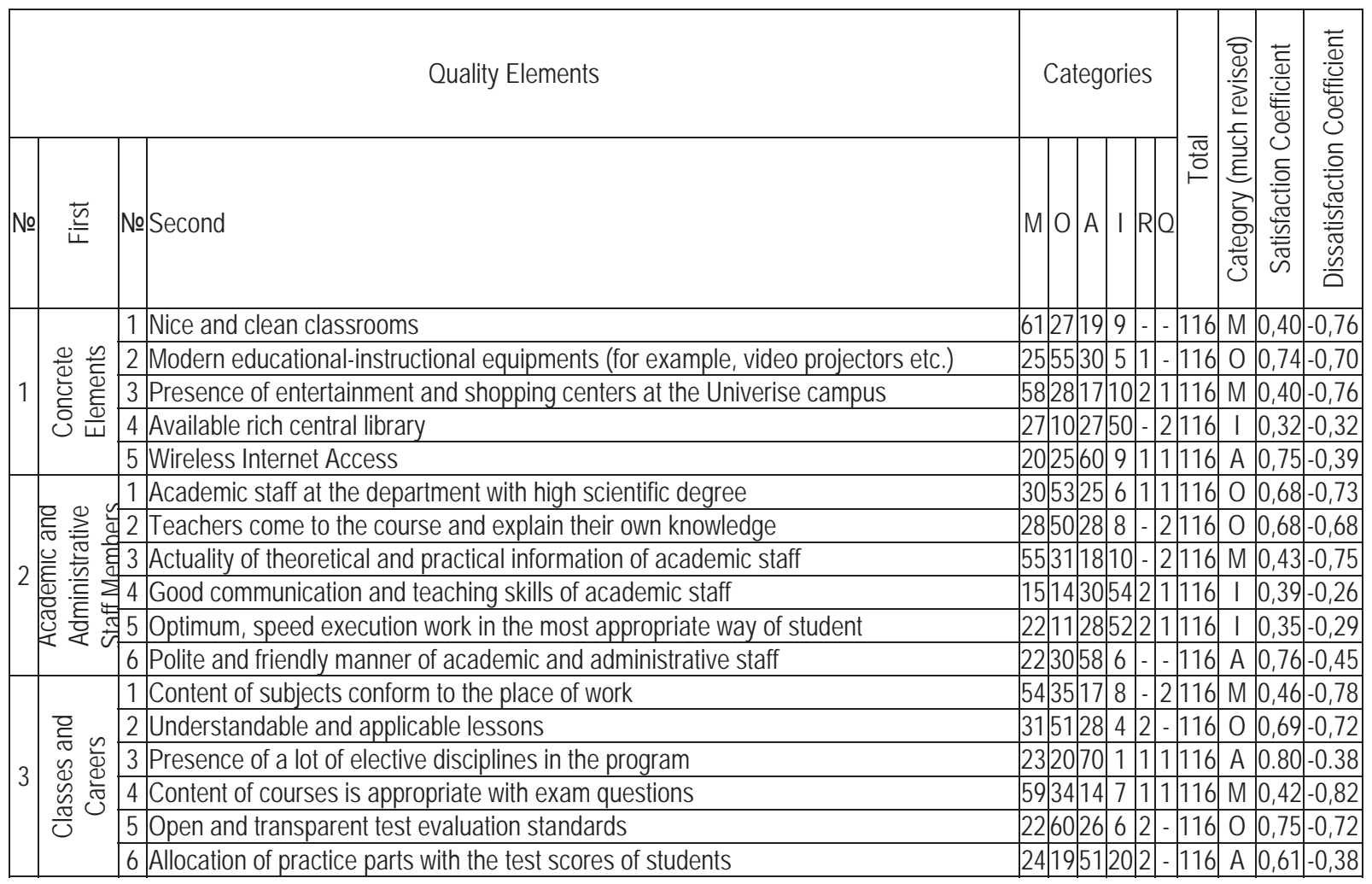




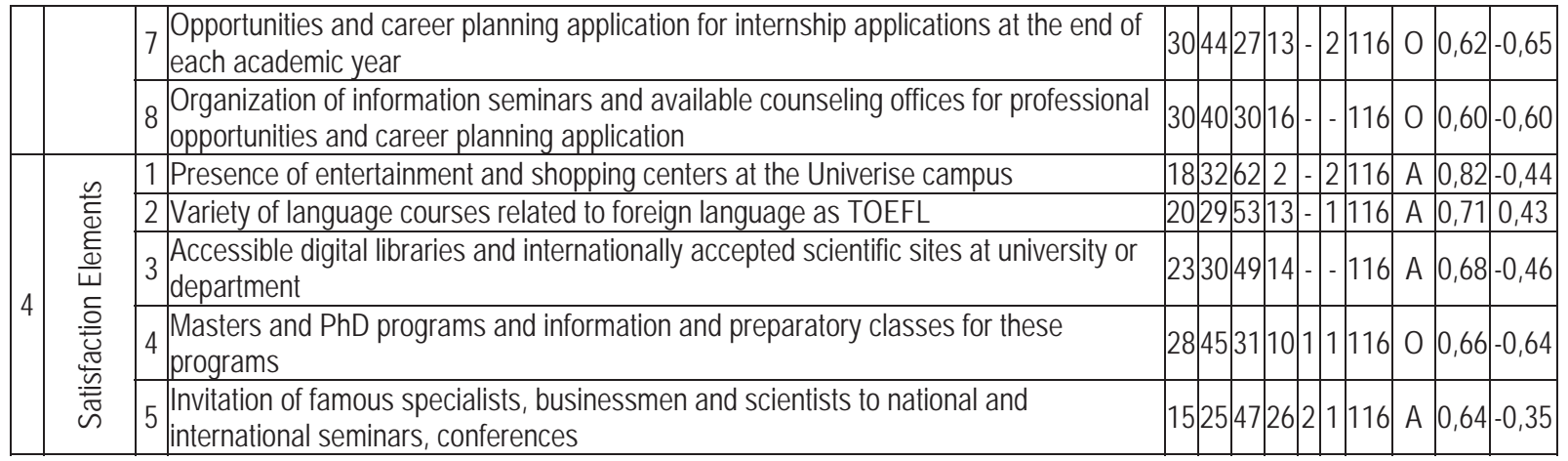

Investigation and Evaluation of the Data: while specified quality requirements are analyzed the frequency analysis, evaluation and satisfaction coefficient table were used. According to the analysis and evaluation of the requirements of 5 based on 24, 8 one-dimensional, 8 attractive and 3 have been identified as indifferent quality requirements. Calculation of requirements satisfaction and dissatisfaction factors identified above requirements to be included in categories more clearly illustrate correct. All of these are detailed in Table 5 (see Table 5).

\section{Conclusions and Recommendations}

As a result of this study, for the purpose of study;

First of all, student satisfactions have been proved according to Kano Questionnaire that was effective in the formation of survey based on student needs. So, 4 primary and 24 secondary quality requirements are defined according to Kano model of higher education institutions as a result of the implementation of university students in their education and training services.

Second, these quality requirements are classified through Kano Rating Tables is basing on this model. So, in the evaluation of the quality requirements specified frequency analysis, evaluation and satisfaction coefficient table were used. According to the analysis and evaluation of 5 requirements over 24 are 'must-be', 8 requirements over 24 are 'onedimensional', 8 requirements over 24 are 'attractive' and 3 requirements over 24 have been identified as 'indifferent quality’ requirements.

Finally, student satisfaction and dissatisfaction with the quality of the programs to analyze their role in improving satisfaction and dissatisfaction coefficients were calculated. Calculation of requirements satisfaction and dissatisfaction factors were identified above these requirements to be included in categories more clearly illustrate correct.

These results are new, detailed information on the detected quality requirements is given as following:

5 must-be quality requirements as specified requirements: classes are nice and clean, the support service units that the academic staff of the theoretical and practical information to be updated, the content of courses is appropriate with exam questions, and the content of subjects taught consistent with each other. These quality requirements are mustbe criteria of educational services. If these requirements are absent at the University or at department, students become extremely dissatisfied. Thus, for the first time Univerisity head should meet these requirements.

8 units specified one-dimensional quality requirements as those: availability of classrooms with modern educational-instructional equipment, presence of high scientific-grade academic staff, teachers of the classes who come and explain own knowledge, understandable and applicable lessons, open and transparent test evaluation standards, the application possibilities and career planning for each academic year at the end of training practices, organization of information seminars and available counseling offices for professional opportunities and career planning application, Masters and PhD programs and information and preparatory classes for these programs. Students' satisfaction is directly proportional to the fulfillment of these requirements. Taking into account these results, University management should increase students' satisfaction and fullfill these requirements for achieving necessary level. In other way, young people who want to study at this department of the University go to other universities or other departments and cause dissatisfaction.

Other 8 of them are identified as attractive quality requirements. These include: wireless internet (wireless) use is open, polite and friendly manner of academic and administrative staff, presence of a lot of elective disciplines in the program, practical activities, part allocation of the test scores, presence of entertainment and shopping centers at the Univerise campus, information studies and a variety of language courses related to foreign language as TOEFL, digital libraries and internationally accepted scientific sites, university or department is accessible to the scientific, professional, 
invitation of experts, businessmen and scientists to national and international seminars and conferences. They have the greatest impact on student quality requirements satisfaction. These quality requirements are not clearly stated and to be expected by the students. However, the fulfillment of the quality requirements and provision of more student satisfaction compared to competitors differentiation of the university or department, allows it to become attractive. Requirements, which are not fulfilled, lead to dissatisfaction of student.

Finally, the remaining three of indifference was identified as quality requirements. These include: a presence of rich central library, good communication skills and the teaching of academic staff and students in the most appropriate way of work is carried out quickly and carefully. These requirements are met, students not to remain indifferent. So, these requirements are not met, does not mean anything for the students, what are neither pleased nor displeased. Therefore, these quality requirements are fulfilled in the University management as not to need to take into account now.

According to these results, one-dimensional quality requirements must be met firstly then must-be and attractive quality requirements. Therefore, students determined and classified according to University and Department should develop themselves in order to meet quality requirements the one-dimensional quality of must-be needs without neglecting the attractive. This is part of the University's, more effective's use of the limited resources, and will provide differentiation compared to its competitors. In conclusion, this study will help university or department management to guarantee the quality of the undergraduate program and to develop further decisions in this direction and develop their own strategies.

\section{References}

Dominici, G. and Palumbo, F. (2013). "How to build an e-learning product: Factors for student/customer satisfaction". Business Horizons, 56, 87-96.

Griffin, A. and Hauser, J. R. (1993). "The Voice of the customer". Marketing Science, 12/1, 1-27.

Harvey, L. (1995). "Student Satisfaction". The New Review of Academic Librarianship, 1/1, 161-173.

http://econ.iktu.kz, Access: 25.10.2014.

Jiao, J. and Chen, C. H. (2006). "Customer requirement management in product development: a review of research issues". Concurrent Engineering: Research and Applications, 14/3, 173-185.

Kano, N. and others (1984). "Attractive quality and must-be quality". Hinshitsu: (The Journal of the Japanese Society for Quality Control), 14/2, 39-48.

Kuo, N. and others (2011). "Identifying critical service quality attributes for higher education in hospitality and tourism: Applications of the Kano Model and importance-performance analysis (IPA)". African Journal of Business Management, 5/30, 12016-12024.

Liu, M. and Wu, S. (2009). "Service quality of student dorms using a refined Kano 2D model: A case study of a national hospitality college in southern Taiwan". Journal of Information \& Optimization Sciences, 30, 481-488.

Liu, M. (2013). "Assessing Student Dormitory Service Quality by Integrating Kano Elaborative Mode with QFD Method - a Case Study in a Hospitality College in Southern Taiwan". Journal of Organizational Innovation, 5/3, 133-150.

Lofgren, M. and Witell, L. (2005). "Kano's Theory of attractive quality and packaging". Quality Management Journal, 12/3, 7-20.

Lofgren, M. and Witell, L. (2008). "Two decades of using Kano's Theory of attractive quality: A literature review". Quality Management Journal, 15/1, 59-75.

Matzler, K. and Hinterhuber, H. H. (1998). "How to make product development projects more successful by integrating Kano's model of customer satisfaction into quality function deployment". Technovation, 18/1, 25-38.

Peters, J.V. (1999). "Total service quality management". Managing Service Quality, 29/1, 6-12.

Pourhasomi, M., Khamseh, A. and Hosseini, S. (2012). "Integrating Kano's Model into QFD to Optimally Identify and Prioritize the Needs of Higher Education". Interdisciplinary Journal of Contemporary Research, 4/4, 233-246.

Tan, K.C. and Pawitra, T. A. (2001). "Integrating SERVQUAL and Kano's Model into QFD for service excellence development". Managing Service Quality, 11/6, 418-430.

Tan, K. C. and Shen, X. X. (2000). "Integrating Kano's Model in the Planning Matrix of Quality Function Deployment". Total Quality Management, 11/8, 1141-1151.

Tontini, G. (2000). "Identification of Customer Attractive and Must-be Requirements Using a Modified Kano's Method: Guidelines and Case Study". ASQ's 54th Annual Quality Congress Proceedings, Brazil, 728-734.

Walden, D. (Ed.). (1993). "Kano's Methods for Understanding Customer-Defined Quality". Center for Quality Management Journal, 2/4, 3-35.

Zultner, R. E. and Mazur, G. H. (2006). "The Kano Model: Recent Developments". The Eighteenth Symposium on Quality Function Deployment, December 2, Austin, Texas, 109-116. 